\title{
LMP1-deficient Epstein-Barr virus mutant requires T cells for lymphomagenesis
}

\author{
Shi-Dong Ma, ${ }^{1}$ Xuequn Xu, ${ }^{2}$ Julie Plowshay, ${ }^{3}$ Erik A. Ranheim, ${ }^{4}$ William J. Burlingham, ${ }^{5}$ Jeffrey L. Jensen, ${ }^{3}$ Fotis Asimakopoulos, ${ }^{3}$ \\ Weihua Tang, ${ }^{6}$ Margaret L. Gulley, ${ }^{7}$ Ethel Cesarman, ${ }^{8}$ Jenny E. Gumperz, ${ }^{2}$ and Shannon C. Kenney ${ }^{1,3}$ \\ Department of Oncology, ${ }^{2}$ Department of Medical Microbiology and Immunology, ${ }^{3}$ Department of Medicine, ${ }^{4}$ Department of Pathology, and ${ }^{5}$ Department of Surgery, School of Medicine and Public Health, \\ University of Wisconsin-Madison, Madison, Wisconsin, USA. ${ }^{6}$ Department of Pathology and Laboratory Medicine, Brody School of Medicine, East Carolina University, Greenville, North Carolina, USA. \\ 'Department of Pathology, University of North Carolina, Chapel Hill, North Carolina, USA. ${ }^{8}$ Department of Pathology and Laboratory Medicine, Weill Cornell Medical College, \\ Cornell University, Ithaca, New York, USA.
}

\begin{abstract}
Epstein-Barr virus (EBV) infection transforms B cells in vitro and is associated with human B cell lymphomas. The major EBV oncoprotein, latent membrane protein 1 (LMP1), mimics constitutively active CD40 and is essential for outgrowth of EBVtransformed B cells in vitro; however, EBV-positive diffuse large B cell lymphomas and Burkitt lymphomas often express little or no LMP1. Thus, EBV may contribute to the development and maintenance of human lymphomas even in the absence of LMP1. Here, we found that i.p. injection of human cord blood mononuclear cells infected with a LMP1-deficient EBV into immunodeficient mice induces B cell lymphomas. In this model, lymphoma development required the presence of CD4+ $T$ cells in cord blood and was inhibited by CD40-blocking Abs. In contrast, LMP1-deficient EBV established persistent latency but did not induce lymphomas when directly injected into mice engrafted with human fetal CD34+ cells and human thymus. WT EBV induced lymphomas in both mouse models and did not require coinjected T cells in the cord blood model. Together, these results demonstrate that $L M P 1$ is not essential for EBV-induced lymphomas in vivo and suggest that T cells supply signals that substitute for LMP1 in EBV-positive B cell lymphomagenesis.
\end{abstract}

\section{Introduction}

The human herpesvirus Epstein-Barr virus (EBV) is associated with various B cell lymphomas, including Burkitt lymphoma (BL), Hodgkin lymphoma (HL), lymphoproliferative disease (LPD) in immunocompromised hosts, and diffuse large B cell lymphomas (DLBCLs) in AIDS patients and the elderly $(1,2)$. The great majority of EBV-infected tumor cells have latent infection, which allows the virus to persist as a nuclear episome that is replicated once per cell cycle using the host cell DNA polymerase (3). At least 3 different forms of viral latency, which differ with respect to the number of viral genes expressed, can occur in EBV-positive tumor cells (3, 4). The only type of EBV infection that is sufficient to transform primary B cells in vitro into long-term lymphoblastoid cell lines (LCLs) is called type III latency; cells with this form of latency express each of the 9 latent viral proteins. Although type III latency is clearly the most transforming form of EBV latency, it is only found in tumors of immunosuppressed patients, since it is also the most immunogenic form.

Latent membrane protein 1 (LMP1), the major EBV oncoprotein, mimics a constitutively active CD40 receptor and interacts

Note regarding evaluation of this manuscript: Manuscripts authored by scientists associated with Duke University, The University of North Carolina at Chapel Hill, Duke-NUS, and the Sanford-Burnham Medical Research Institute are handled not by members of the editorial board but rather by the science editors, who consult with selected external editors and reviewers.

Conflict of interest: The authors have declared that no conflict of interest exists. Submitted: March 31, 2014; Accepted: October 31, 2014.

Reference information: J Clin Invest. 2015;125(1):304-315. doi:10.1172/JCI76357. with cellular TNF receptor-associated factor (TRAF) proteins to induce various downstream pathways (including NF- $\mathrm{KB}, \mathrm{PI} 3 \mathrm{~K}$, and STAT3) that promote B cell proliferation and apoptosis resistance (5-8). Although LMP1 is essential for the long-term outgrowth of EBV-transformed LCLs in vitro in the absence of a feeder layer (9), EBV-positive lymphomas in vivo often have more restricted forms of viral latency. For example, EBV-positive BLs, which are largely driven by MYC translocations, usually express only the EBNA1 protein (required for latent EBV genome maintenance), in addition to the virally encoded microRNAs and EBV-encoded small nuclear RNAs (EBER) $(1,2,10,11)$. Furthermore, the majority of EBV-positive AIDS-related DLBCLs do not express detectable LMP1 protein (12). Thus, EBV appears to promote the growth of human tumors such as DLBCLs and BLs even in the absence of LMP1 expression. However, since EBV cannot replicate in nonprimate cells, it has been difficult to develop small animal models to study how EBV infection might drive the development of B cell lymphomas in the absence of LMP1 expression.

One of the key factors that likely influences LMP1 expression in vivo is its comparatively high immunogenicity for T cells, which leads to increased targeting of $\mathrm{LMP}^{+}$cells by cytotoxic $\mathrm{T}$ lymphocytes (CTLs) (13). Levels of LMP1 protein within LCLs have been found to vary over a 10 -fold range, and to cycle over time (14-16). Cells with the highest level of LMP1 have enhanced MHC class I expression and are preferentially killed by T cells in vitro (14). In addition, LMP1 activates CD95 expression, promoting FAS-mediated killing by T cells (17). Moreover, LMP1 induced early-onset B cell lymphomas in a recent LMP1 transgenic mouse model only when $\mathrm{T}$ cell function was inhibited, since $\mathrm{LMP} 1^{+} \mathrm{B}$ 


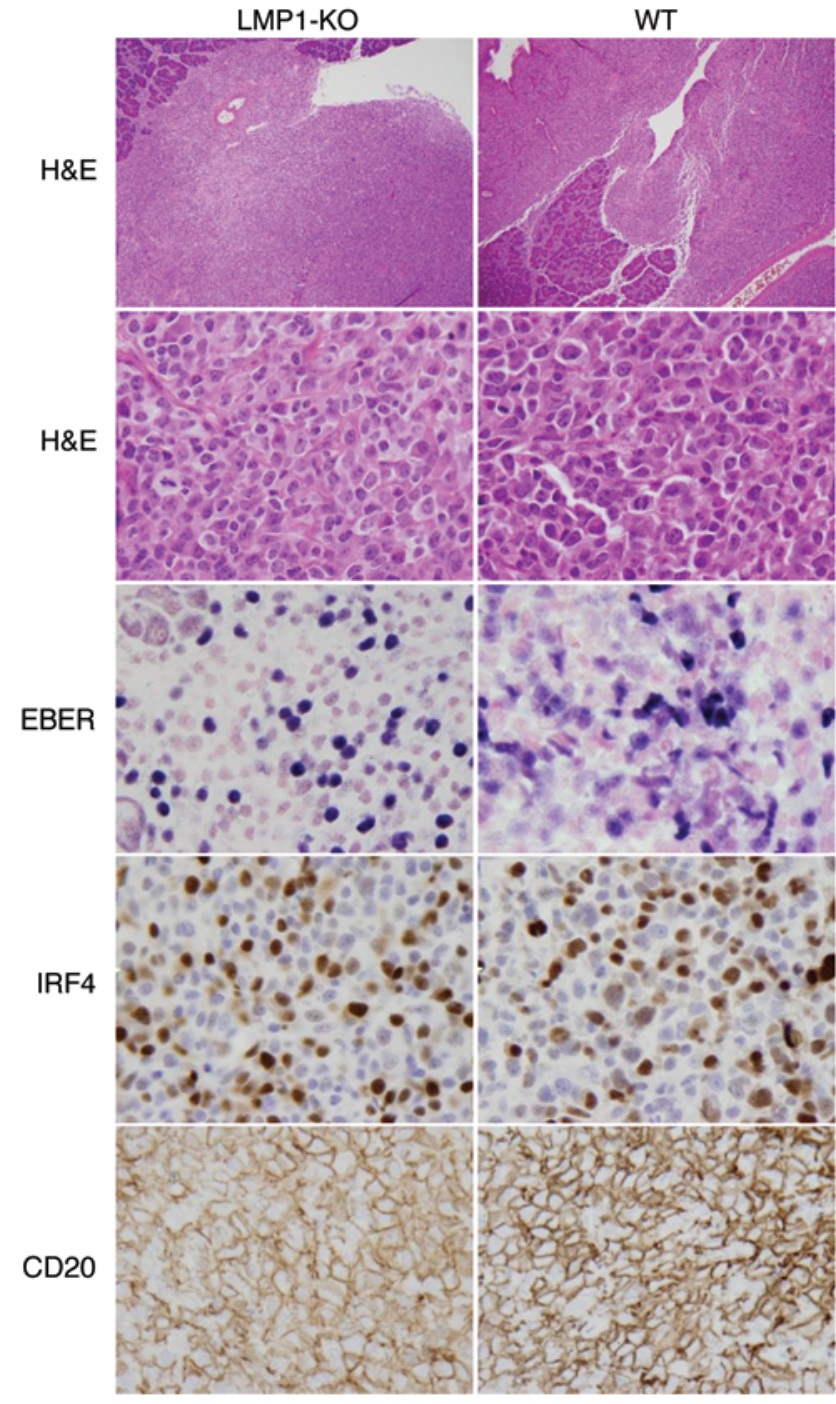

Figure 1. LMP1-KO EBV-infected human cord blood induces invasive lymphomas in NSG mice. Representative H\&E-stained LMP1-KO EBV- and WT EBV-infected lymphomas invading the pancreas. EBER was detected by ISH, and cellular proteins IRF4 and CD2O were detected by IHC. Original magnification, $\times 10$ (top row), $\times 100$ (bottom rows).

cells were otherwise eliminated by $\mathrm{T}$ cell-mediated killing (13). Thus, while LMP1 may promote B cell lymphomas by its CD40like signaling effects, it also enhances killing of EBV-infected B cells by functional $\mathrm{T}$ cells.

The main route by which CD40 signaling is mediated in $\mathrm{B}$ cells is via contact with activated Tymphocytes that have upregulated expression of CD40 ligand (CD4OL) at the cell surface (6). It is not known whether activated $\mathrm{T}$ cells expressing CD4OL can substitute for the transforming function(s) of LMP1 in vivo, provided the $\mathrm{T}$ cells cannot efficiently kill the EBV-infected $\mathrm{B}$ cells. However, cord blood-derived helper $\mathrm{T}$ cells have been reported to increase the ability of EBV to transform cord blood-derived B cells in vitro by 10-fold (18). Interestingly, the ability of peripheral blood lymphocytes from healthy EBV-seropositive humans to induce EBV-positive B cell lymphomas in SCID mice requires the presence of coinjected T cells (19-23), although established LCLs can induce lymphomas in SCID mice without $\mathrm{T}$ cells.
Thus, in order to understand the counterbalancing role(s) of LMP1 in lymphoma induction, it is important to study its effects in the context of the intact virus, and in the presence and absence of $\mathrm{T}$ cells that may more efficiently target $\mathrm{LMP}^{+}$cells for cytolysis or may provide signals that can substitute for its effects on B cells. NOD/LtSz-scid/IL2R $\gamma^{\text {null }}$ (NSG) mice reconstituted with human immune cells represent an excellent small-animal model for studying the roles of specific EBV proteins in the development of B cell lymphomas in the presence of a host immune response (24-29). NSG mice engrafted with both human fetal hematopoietic stem cells and thymic tissue [referred to herein as hNSG(thy) mice] support significant levels of $\mathrm{T}$ cell function (30). In previous studies, we showed that EBV (B95.8 strain) infection in hNSG(thy) mice induces EBV-positive DLBCLs in a subset of infected mice, while the rest of the mice successfully control their EBV infection and develop long-term (tumor-free) viral latency $(26,27)$. Furthermore, we found that alteration of T cell function in hNSG(thy) mice using the anti-CD3 $\mathrm{mAb}$ OKT3 (which initially activates $\mathrm{T}$ cells and then depletes them) greatly increases the number and size of EBVinfected lymphomas in this humanized mouse model (27).

Although hNSG(thy) mice provide an excellent model for understanding how the host immune response controls EBV infection and prevents lymphomas, such mice are expensive and technically difficult to make and require the use of human fetal tissue. In addition, since even WT EBV infection results in relatively few lymphomas in this model, humanized NSG models that are less immunocompetent may be more useful for studying the role of various EBV genes in the development of EBV-induced lymphomas.

Here, we demonstrated that cord blood cells infected briefly in vitro with either WT EBV or the LMP1-deleted EBV mutant (referred to herein as LMP1-KO EBV) caused lymphomas when injected into NSG mice. However, in contrast to the WT EBVinduced lymphomas, the LMP1-KO EBV-induced lymphomas required the presence of human $\mathrm{CD}^{+} \mathrm{T}$ cells. Furthermore, we showed that a CD40-blocking Ab inhibited cord blood lymphomas induced by either WT EBV or LMP1-KO EBV. In the more immunocompetent hNSG(thy) humanized mouse model, WT EBV induced lymphomas more efficiently than LMP1-KO EBV, although the latter could establish persistent viral latency. These results indicate that $\mathrm{T}$ cells can both promote and inhibit EBVinduced B cell lymphomas, depending on the quality of the $\mathrm{T}$ cell response and the presence of LMP1 expression. Our findings also suggest that CD40-blocking Abs may be a promising approach for treating certain types of EBV-induced lymphomas.

\section{Results}

LMP1-KO EBV induces cord blood-derived lymphomas in NSG mice. To determine whether EBV can induce lymphomas in vivo even in the absence of LMP1 expression, we developed a model system in which CD34-depeleted human cord blood cells were either mock-infected or infected for 1.5 hours in vitro with 30,000 infectious particles of WT or LMP1-KO EBV, then injected i.p. into NSG mice. The presence of EBV infection and EBV lymphomas was then determined using the same methods described for our previous studies of EBV infection in hNSG(thy) mice (26). In the cord blood model, WT EBV-infected mice generally developed tumor symptoms requiring euthanasia 30-40 days after infection. 
A

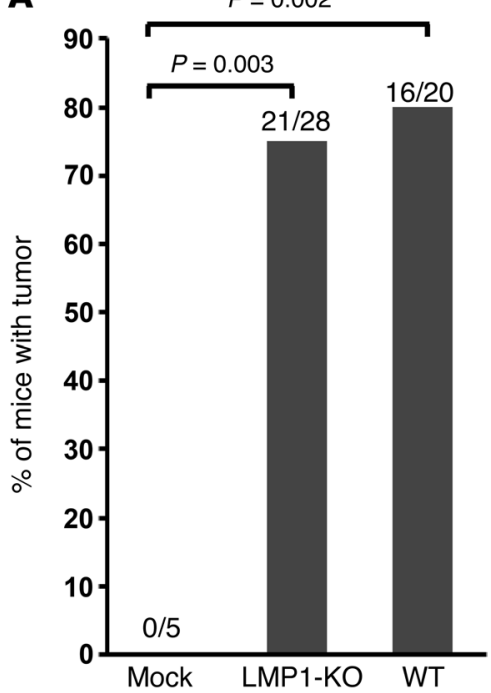

B

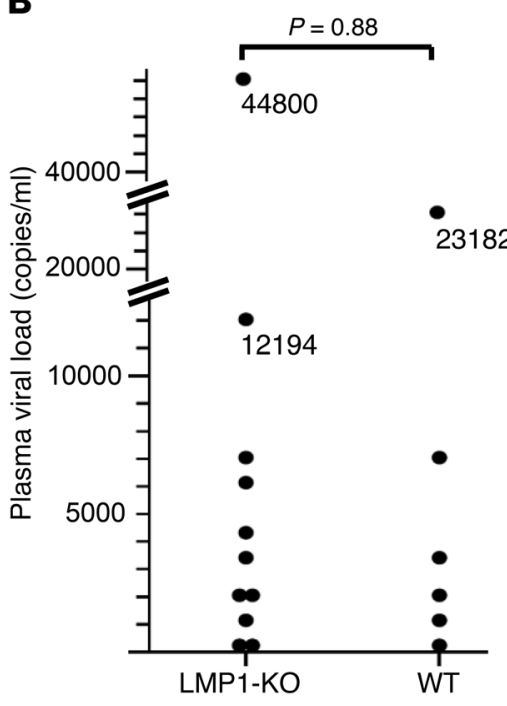

Figure 2. WT and LMP1-KO EBV-infected cord blood cells, but not mock-infected cells, promote lymphomas in NSG mice. (A) Incidence and percentage of NSG mice developing lymphomas after injection with mock-infected, WT EBV-infected, or LMP1-KO EBV-infected human cord blood. 6 experiments were performed; 2-tailed Fisher exact test was used for statistical analysis. (B) EBV plasma viral loads (obtained at the time of euthanasia) in mice injected with WT EBV- or LMP1-KO EBV-infected cord blood. Animal plasma from 3 experiments were used for testing viral loads; Wilcoxon rank-sum test was used for statistical analysis. For the animals with very high plasma viral loads, exact values are shown.

tumors have type III latency, RNA was isolated from tumor cells, reversed transcribed, and PCR amplified using primers specific for the type III (Cp promoter) and type I/II (Qp promoter) forms of the EBNA transcript. The type III form of the EBNA transcript was detected in LMP1-KO EBV-infected tumor cells, but the type I/II form was not (Figure 3B). Although LMP1 has been reported to inhibit lytic viral reactivation (31), very few LMP1-KO EBVinfected (or WT EBV-infected) cord blood lymphoma cells expressed the EBV immediate-early lytic protein, BZLF1 (data not shown). Both WT EBV- and LMP1-KO EBV-infected cord blood cell lymphomas were heavily infiltrated by T cells, as assessed by the number of cells staining positively for CD3 within the tumors (Figure $3 \mathrm{~A}$ and data not shown).

Both WT EBV- and LMP1-KO EBV-infected cord blood lymphomas showed numerous cells staining positively for the proliferation marker Ki67 (Figure 4, A and B). WT EBV- and LMP1-KO EBV-induced tumors were also both positive for expression of MYC (Figure 4B), which is known to be activated by the EBNA2 viral protein. WT EBV- and LMP1-KO EBV-induced lymphomas also showed strong staining for the transcription factor IRF4 (also known as MUM-1) (Figure 1 and Figure 4A), a marker for early plasma cell differentiation as well as an essential sur-

NSG mice injected with LMP1-KO EBV- or WT EBV-infected blood developed EBV-positive lymphomas (Figure 1). Both the WT EBV- and the LMP1-KO EBV-infected lymphomas were often clearly invasive, and both had phenotypes similar to the activated form of human DLBCL. Lymphomas occurred most commonly in the pancreas, gallbladder, liver and mesentery. Cord blood infected with either WT EBV or LMP1-KO EBV produced B cell lymphomas in the majority of injected NSG mice, and resulted in similar EBV loads, although WT EBV-infected lymphomas were often (but not always) larger than the LMP1-KO EBV-infected lymphomas derived from the same cord blood donor (Figure 2 and data not shown). In contrast, none of the mock-infected cord blood cell-injected animals developed lymphomas or had detectable EBV loads (Figure 2 and data not shown). Moreover, in mice injected with mock-infected cord blood, the human B cells engrafted very poorly and were often undetectable at the end of the experiment, whereas the human $\mathrm{T}$ cells expanded and persisted for more than 4 weeks (data not shown).

Both WT EBV- and LMP1-KO EBV-induced cord blood lymphomas expressed the $\mathrm{B}$ cell marker $\mathrm{CD} 20$ and the viral protein EBNA2 (Figure 1, Figure 3A, and data not shown), suggestive of type III viral latency. To confirm that LMP1-KO EBV-infected

Figure 3. LMP1-KO EBV-infected cord blood lymphomas have type III latency and are heavily infiltrated by T cells. (A) An LMP1-KO EBV-infected cord blood lymphoma invading the pancreas was stained for H\&E, EBV EBNA2 protein, $C D 20$, and CD3. The lymphoma was EBNA2 $2^{+}$and $C D 20^{+}$ and infiltrated by numerous $\mathrm{CD}^{+} \mathrm{T}$ cells. Original magnification, $\times 40$. (B) RT-PCR was performed on RNA isolated from 2 different LMP1-KO EBVinfected tumors to detect Qp- and Cp-derived EBNA transcripts. Mutu I (type I latency) and Kem III (type III latency) cells were used as controls. vival factor both for EBV-transformed LCLs in vitro $(32,33)$ and for activated DLBCLs (34), HLs (35), and multiple myeloma tumors in vivo (36). IRF4 is also a surrogate immunohistochemical (IHC) marker for the more aggressive "activated B cell" type of DLBCL.

To ensure that lymphomas observed in mice injected with the LMP1-KO EBV-infected cord blood cells were free of any WT EBV, we performed IHC to detect LMP1 expression on WT EBV- versus LMP1-KO EBV-induced lymphomas (Figure 5A). As expected, some of the tumor cells in animals given WT EBVinfected cord blood expressed LMP1, but no LMP1 staining was

A

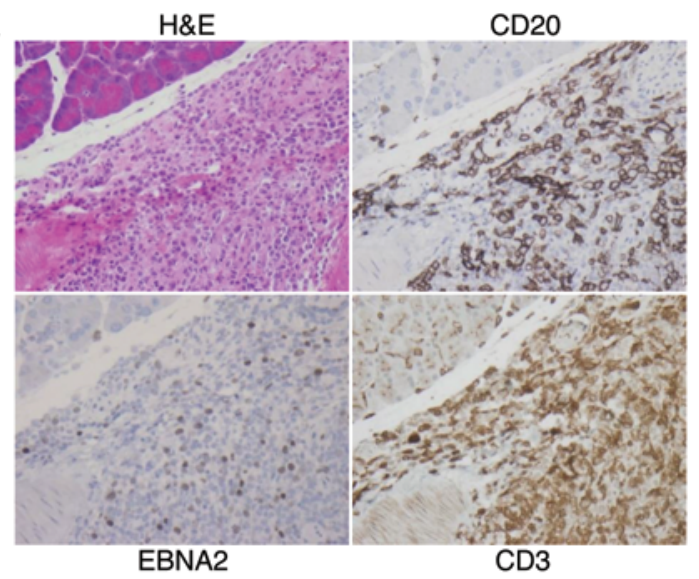

B

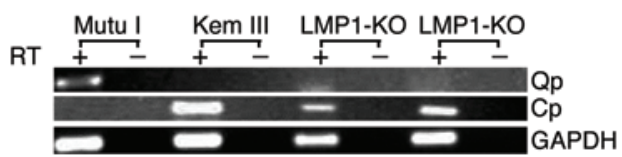


A

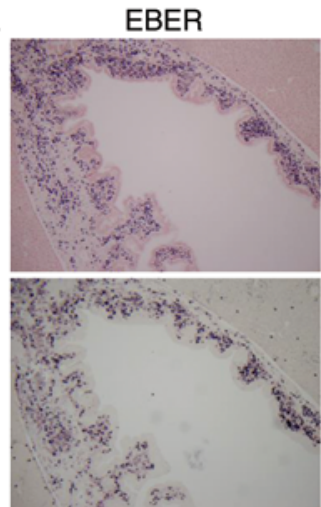

Ki67

B

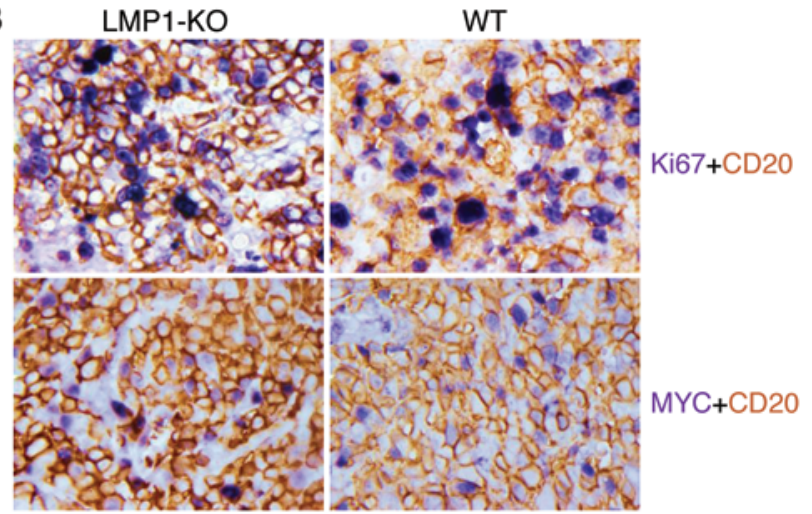

observed in those given LMP1-KO EBV-infected cells. To further confirm the lack of LMP1 gene expression in LMP1-KO tumors, we isolated DNA from paraffin-fixed slides of WT EBV- or LMP1-KO EBV-induced tumors and performed PCR analysis using primers that can amplify either the viral $B Z L F 1$ promoter sequences or the $L M P 1$ gene; whereas both were amplified using the WT tumor DNA, only the BZLF1 promoter sequences could be amplified using the LMP1-KO EBV tumor DNA (Figure 5B).

To assess whether LMP1-KO EBV-induced lymphomas are clonal or polyclonal, we used IHC to examine the type of Ig light chains expressed by B cells in the tumors. As shown in Figure 6, some of the larger and more invasive LMP1-KO EBV-induced lymphomas (including that shown in Figure 1) were likely monoclonal, based on their preferential expression of $\kappa$ versus $\lambda$ light chains. However, smaller and less invasive LMP1-KO EBV-induced lymphomas (including the gallbladder wall lymphoma shown in Figure $4 \mathrm{~A}$ ) were likely polyclonal, as assessed by the presence of positive staining for both light chain types within the tumor (data not shown). WT EBV- and LMP1-KO EBV-induced lymphomas had a similar distribution of monoclonal versus polyclonal tumors and an apparent preference for the $\kappa$ light chain rearrangement (Supplemental Table 1; supplemental material available online with this article; doi:10.1172/JCI76357DS1). The finding that some LMP1-KO EBV-induced lymphomas were initially polyclonal suggests that at least the smaller tumors are driven largely by EBV infection, rather than secondary cellular mutations.

$T$ cells support the development of LMP1-KO EBV-infected cord blood lymphomas in NSG mice. The ability of the LMP1-KO EBVinfected cord blood to induce lymphomas in NSG mice was unex-
Figure 4. LMP1-KO EBV-induced lymphomas are highly proliferative, activated DLBCLs that express c-MYC. (A) LMP1-KO EBV-infected B cells infiltrating the gall bladder wall expressed EBER, CD20, Ki67, and IRF4. (B) Representative LMP1-KO EBV- and WT EBV-infected lymphomas invading the pancreas, stained for either Ki67 or c-MYC (purple) and costained with CD20 (brown). Original magnification, $\times 10$ (A); ×100 (B).

pected, given the severe transformation defect of this mutant in vitro (9). However, the LMP1-KO mutant can transform B cells in vitro with very low efficiency (less than $1 \%$ the efficiency of WT EBV) when infected cells are grown continuously on a feeder cell layer (9). Since T cells are required for the ability of EBV-induced lymphomas to form when peripheral blood lymphocytes from EBVpositive donors are injected into SCID mice (19-22), we hypothesized that $\mathrm{T}$ cells may likewise support the growth of LMP1-KO EBV-infected cord blood B cells in humanized NSG mice.

To assess this, total cord blood cells or T cell-depleted fractions were infected with WT EBV or LMP1-KO EBV, then injected into NSG mice. LMP1-KO EBV-infected cord blood did not induce lymphomas when $\mathrm{T}$ cells were depleted (Figure 7A). In contrast, lymphomas were induced in mice injected with WT EBV-infected cord blood, regardless of whether the $\mathrm{T}$ cells had been depleted. These results suggest that the B cells infected with LMP1-KO EBV, but not WT EBV, are dependent on T cell-derived factors for their expansion into lymphomas in NSG mice.

$C D 4^{+} T$ cells are required for growth of LMP1-KO EBV-infected, but not WT EBV-infected, cord blood lymphomas. To determine whether $\mathrm{CD} 4^{+} \mathrm{T}$ cells are required for the establishment of LMP1KO EBV-infected lymphomas in the cord blood model, mice were injected with either WT EBV- or LMP1-KO EBV-infected cord blood cells, then treated with or without a $\mathrm{CD} 4^{+} \mathrm{T}$ cell-depleting $\mathrm{Ab}$ (CD4R1) starting at day 4 after injection. Anti-CD4 treatment

A

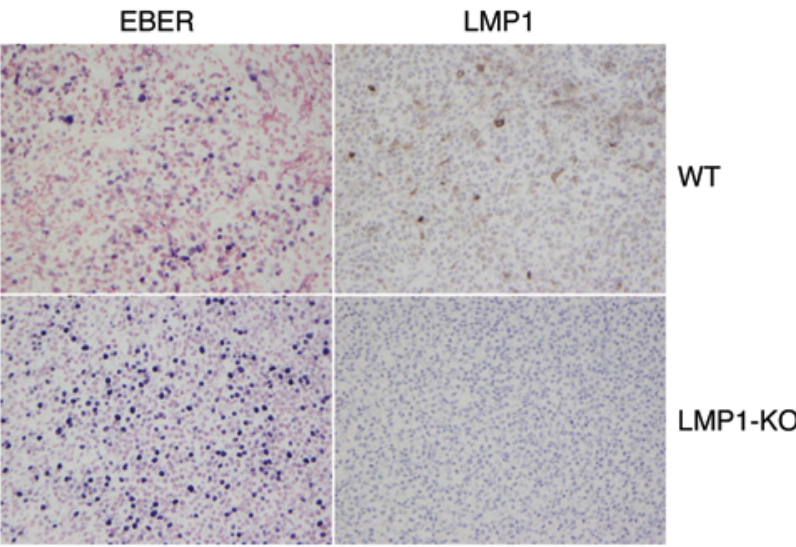

B

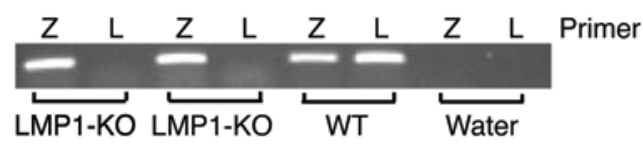

Figure 5. LMP1-KO EBV-induced lymphomas do not express LMP1. (A) EBER ISH and LMP1 IHC staining of representative WT EBV- and LMP1-KO EBV-infected cord blood lymphomas. Original magnification, $\times 20$. (B) PCR analysis was performed on isolated tumor DNA prepared from 1 WT EBV-infected tumor, 2 different LMP1-KO EBV-infected tumors, or water control, using primers that amplify the $L M P 1$ gene $(L)$ or the viral BZLF1 promoter (Z). 


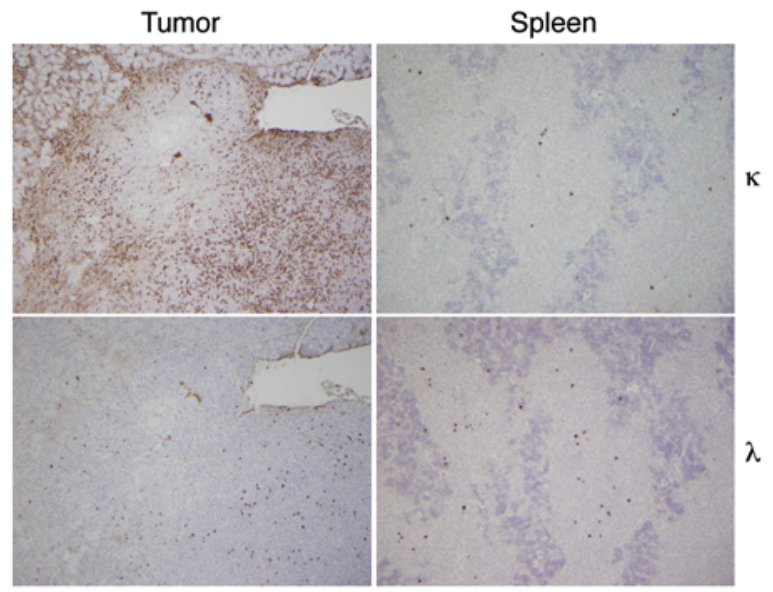

Figure 6. LMP1-KO EBV-infected cord blood lymphomas can become monoclonal. IHC staining using $\kappa$ - and $\lambda$-specific light chain Abs revealed $\kappa$ light chain dominance in an LMP1-KO EBV-infected pancreatic lymphoma as well as polyclonality in the spleen tissue from same animal. Original magnification, $\times 10$.

inhibited the ability of LMP1-KO EBV to establish lymphomas, whereas WT EBV successfully established lymphomas even when the $\mathrm{CD}^{+} \mathrm{T}$ cells were depleted (Figure $7 \mathrm{~B}$ ). These results confirmed that $\mathrm{CD}^{+} \mathrm{T}$ cells support the growth of LMP1-KO EBVinfected B cells in the humanized cord blood model.

CD4O-blocking Ab inhibits both WT EBV- and LMP1-KO $E B V$-induced cord blood lymphomas in NSG mice. A major pathway by which activated $\mathrm{CD} 4^{+} \mathrm{T}$ cells induce the proliferation and survival of B cells is by providing a source of CD4OL to CD40expressing B cells (6). Although LMP1 is thought to mimic the effect of constitutively active CD40 signaling, a previous in vitro study showed that WT EBV was not able to transform B cells obtained from patients with hyper-IgM syndrome, who have inactivating mutations of the gene encoding CD4OL (37). Thus, expression of LMP1 as a result of EBV infection may not completely substitute for authentic CD40 signaling in B cells.

To determine whether CD40 signaling is required for the ability of either WT EBV or LMP1-KO EBV to induce cord blood lymphomas in NSG mice, WT EBVand LMP1-KO EBV-infected mice were treated or not with the CD40-blocking Ab 2C10R4 (100 $\mu$ g per animal injected i.p. 3 times per week, starting 1 day after infection). This $\mathrm{Ab}$ has been previously shown to block CD40 signaling in vitro and to greatly prolong the survival of pancreatic islet cell allograft transplants in rhesus macaques without significantly affecting peripheral B cell numbers (38). Anti-CD40 treatment inhibited the development of lymphomas in animals injected with LMP1-KO EBV-infected cord blood and also decreased the number of lymphomas induced by WT EBV (Figure 8A). Notably, WT EBV-induced tumors observed in the presence of CD40 Ab were very small (data not shown). Anti-CD40 treatment did not prevent engraftment of human T cells, and both WT EBV and LMP1-KO EBV established persistent viral latency in the presence of the
$\mathrm{Ab}$ (Figure 8B and data not shown). Thus, CD40 blockade specifically inhibited outgrowth of EBV-transformed B cells, while not preventing viral infection.

WT EBV-infected, but not LMP1-KO EBV-infected, B cells express CD4OL in the humanized cord blood model. The findings that both WT EBV- and LMP1-KO EBV-induced tumors were inhibited by the CD40-blocking Ab, yet only the LMP1-KO EBVinfected tumors were inhibited by $\mathrm{T}$ cell depletion, suggested that WT EBV-infected B cells may express CD4OL and thus not depend on T cells as a source of CD4OL stimulation. To examine this possibility, CD4OL expression on the surface of B cells and T cells was examined using FACS analysis in tumors and spleens isolated from animals injected with WT EBV- or LMP1-KO EBVinfected cord blood cells. CD4OL was expressed on a portion of T cells in animals infected with either EBV, but only B cells infected with WT EBV expressed CD4OL (Figure 9A). Although we did not always detect CD40L expression on tumor B cells from WT EBV-infected mice (presumably as a function of the changing phenotype of tumor B cells as the tumors progressed), when we were able to detect CD40L expression on B cells, it was associated with WT EBV infection; we never saw CD40L on B cells from LMP1-KO EBV-infected mice. This result suggests that the dependence of LMP1-KO EBV-derived tumors, but not WT EBVderived tumors, on coinjected $\mathrm{CD} 4^{+} \mathrm{T}$ cells is at least partially due to the lack of CD4OL expression in LMP1-KO EBV-infected B cells. Notably, we also found that splenic T cells in EBV-infected, but not uninfected, human cord blood-injected mice expressed CD40L (Supplemental Figure 1). This result suggests that T cells are the source of CD4OL that stimulates LMP1-KO EBV-infected $\mathrm{B}$ cell growth, and that $\mathrm{T}$ cell activation occurs in response to EBV infection. The T cells also typically expressed high levels of the B cell growth factor BAFF in both WT EBV- and LMP1-KO
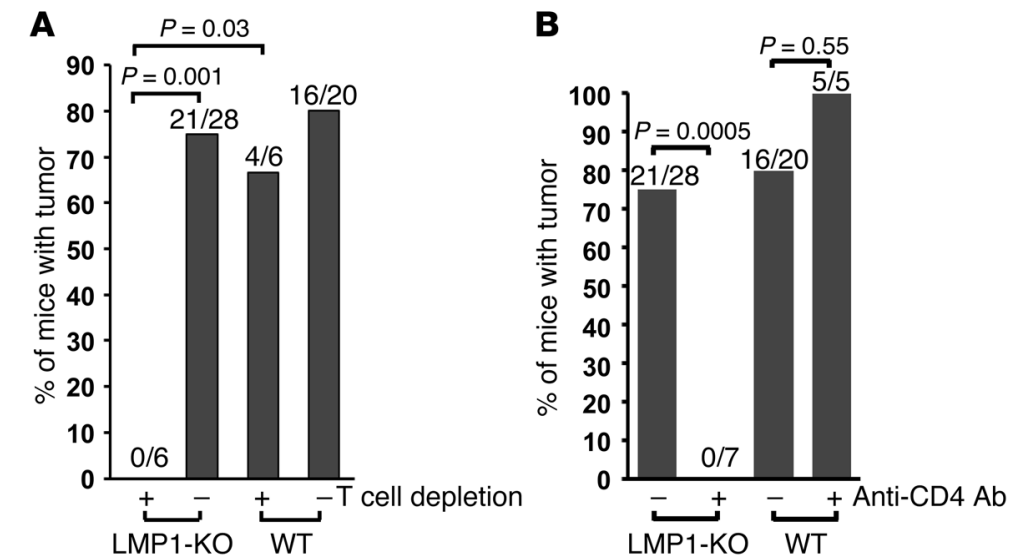

Figure 7. CD4 ${ }^{+} \mathrm{T}$ cells support the growth of LMP1-KO EBV-induced cord blood lymphomas in NSG mice. (A) Incidence and percentage of NSG mice that developed Iymphomas after injection with WT EBV- or LMP1-KO EBV-infected human cord blood in the presence or absence of T cell-depleting treatments. Data were derived by combining the results of 2 experiments each with and without T cell depletion and of 4 nondepletion experiments; 2-tailed Fisher exact test was used for statistical analysis. (B) Incidence and percentage of NSG mice developing lymphomas after injection with WT EBV- or LMP1-KO EBV-infected human cord blood in the presence or absence of $\mathrm{CD} 4^{+} \mathrm{T}$ cell-depleting Ab (CD4R1). Data were derived by combining the results of 2 experiments each with and without anti-CD4 Ab and of 4 no-Ab experiments; 2-tailed Fisher exact test was used for statistical analysis. 


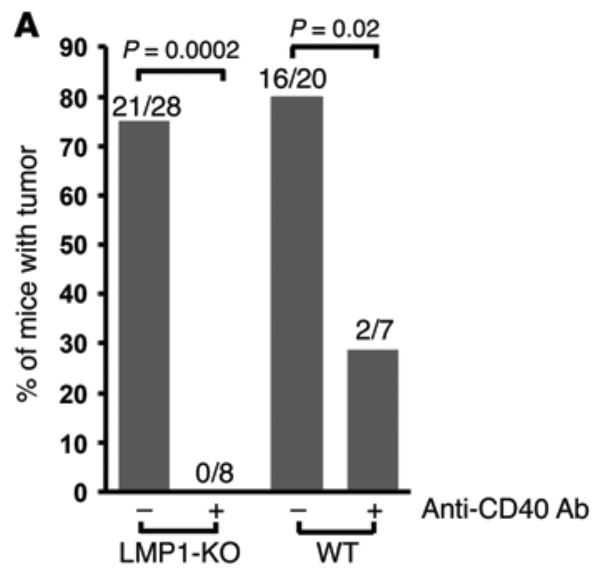

B

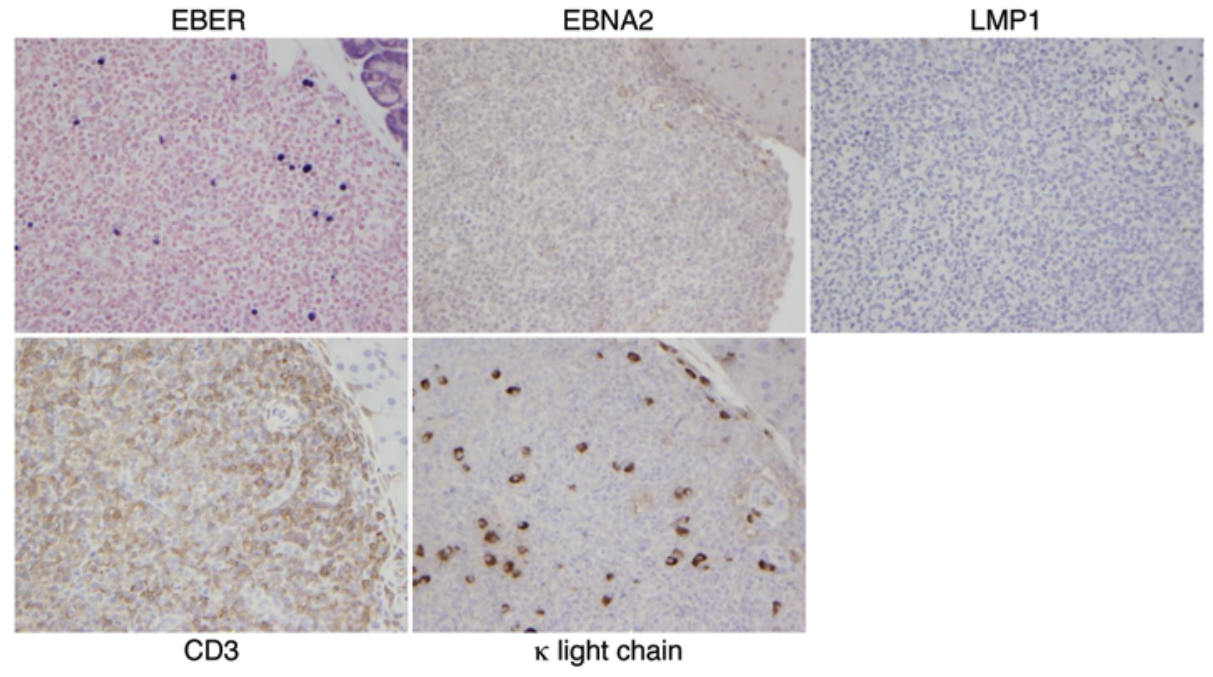

Figure 8. CD40 signaling supports the growth of both WT EBV- and LMP1-KO EBV-induced cord blood lymphomas in NSG mice. (A) Incidence and percentage of NSG mice developing lymphomas after injection with WT EBV- or LMP1-KO EBV-infected human cord blood in the presence or absence of CD40-blocking Ab. Data were derived by combining the results of 2 experiments each with and without anti-CD40 Ab and of 4 no-Ab experiments; 2-tailed Fisher exact test was used for statistical analysis. (B) A peripancreatic granuloma-like lesion in a NSC mouse injected with WT EBVinfected cord blood and treated with CD40-blocking Ab, stained for EBER, EBNA2, LMP1, CD3, and $\kappa$ light chain. EBV-infected $B$ cells were surrounded by $T$ cells. Original magnification, $\times 40$.
EBV-infected animals (Figure 9B), which suggests that there may be other pathways, in addition to CD4OL, by which $\mathrm{T}$ cells can enhance the growth of EBV-infected B cells.

The LMP1-KO mutant is defective for inducing lymphomas in hNSG(thy) mice, but can establish persistent latent infection. Since we previously showed that a subset of WT EBV-infected hNSG(thy) mice (engrafted with both human fetal HSCs and fetal thymus) eventually develop EBV-positive DLBCLs $(26,27)$, we also examined the ability of LMP1-KO EBV to induce lymphomas in this more immunocompetent humanized mouse model. Whereas 0 of 9 LMP1-KO EBV-infected hNSG(thy) animals developed lymphomas, 8 of 21 of the WT EBV-infected (B95.8 strain) hNSG(thy) animals - some of which were historical controls - developed lymphomas (Figure 10). This result suggests that WT EBV is more transforming than LMP1-KO EBV in this model.

Because it is currently unknown whether LMP1 is required for establishment of persistent viral latency in immunocompetent humans, we also sought to determine whether LMP1KO EBV can establish persistent latent viral infection in the hNSG(thy) model. Animals were considered to be persistently infected if, when euthanized 30-60 days after infection, they had 1 or more of the following: (a) EBER ${ }^{+}$cells on paraffin-fixed sections of various organs (including spleen, liver, mesentery, pancreas, lungs, and gastrointestinal tract); (b) EBNA1 $^{+}$or EBNA2 $^{+}$cells, detected by IHC of paraffin-fixed tissue; or (c) detectable EBV viral load in the blood, determined by quantitative real-time PCR (Q-PCR). The majority of LMP1-KO EBVinfected hNSG(thy) mice had persistent latent viral infection, similar to the number of WT EBV-infected hNSG(thy) animals (Figure 10). While both stringent $\left(\mathrm{EBER}^{+}\right.$cells without detectable EBNA1) and less-stringent (EBNA1 ${ }^{+}$or $\mathrm{EBNA}^{+}$) forms of viral latency were observed, lytically infected, BZLF1 ${ }^{+}$cells were not detected (Figure 10D). As expected, mock-infected hNSG(thy) animals had no evidence of EBV infection in any of these 3 assays (data not shown). Together, these results indicate that LMP1 expression enhances (and may be required for) the ability of EBV to induce DLBCLs in humanized mice when $\mathrm{T}$ cells are highly functional, but is not required for the ability of EBV to establish persistent latent infection.

LMP1-KO EBV can induce lymphomas in hNSG(thy) mice treated with the anti-CD3 $m A b$ OKT3. Since we found that almost all WT EBV-infected hNSG(thy) mice developed very large lymphomas when $\mathrm{T}$ cell function was altered by treating mice with OKT3, which binds to the CD3 complex of T cells, we next examined whether LMP1-KO EBV can induce lymphomas in hNSG(thy) animals treated with this mAb. Of the LMP1-KO EBV-infected hNSG(thy) mice, 3 of 7 treated with OKT3 developed lymphomas, compared with 5 of 6 WT EBV-infected hNSG(thy) mice treated with OKT3 (Figure 11A). Notably, the lymphomas in OKT3-treated hNSG(thy) mice infected with WT EBV were usu- 


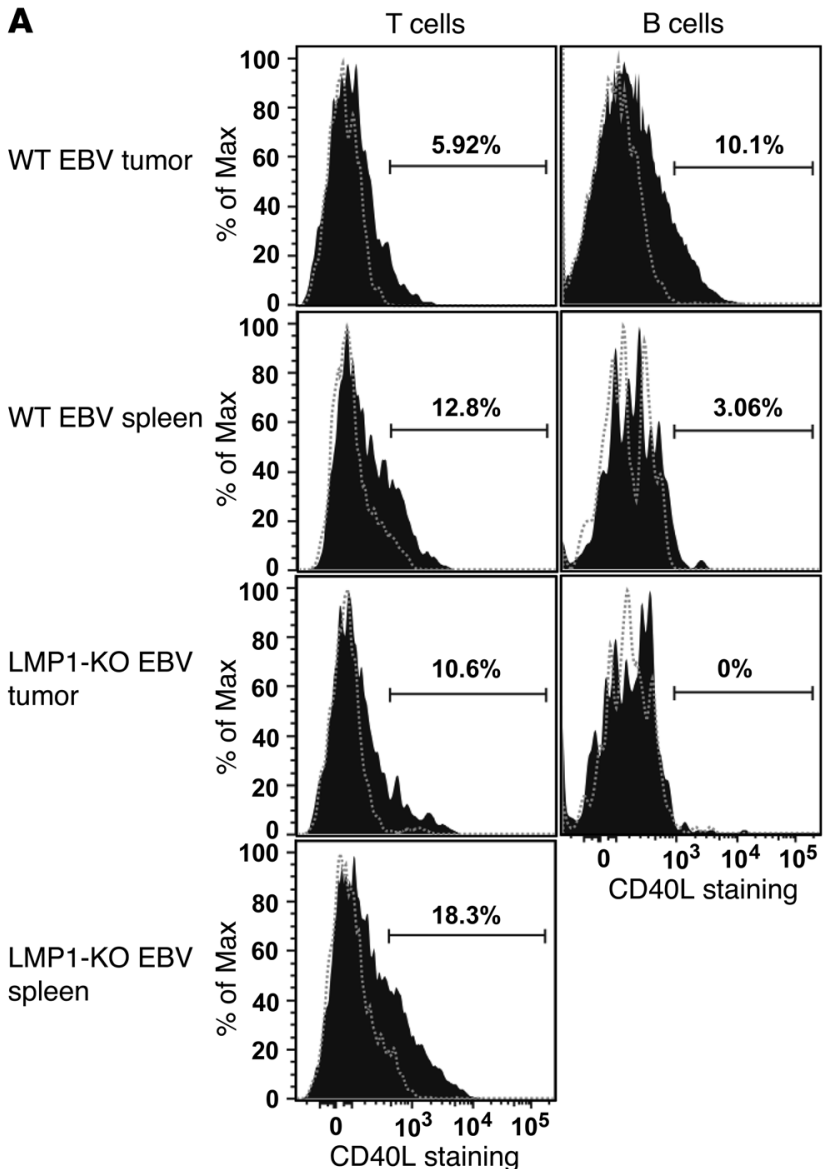

ally much larger than those induced by LMP1-KO EBV (data not shown). The LMP1-KO EBV-induced lymphomas in OKT3-treated hNSG(thy) mice had phenotypes similar to activated human DLBCLs, expressed CD20 and IRF4 (Figure 11B), and had type III latency. Since OKT3 induces both T cell activation $(39,40)$ and eventual clearance of $\mathrm{T}$ cells in vivo, its observed ability to increase the frequency of lymphomas induced by LMP1-KO EBV in hNSG(thy) mice could be due to enhanced growth signals derived from activated $\mathrm{T}$ cells and/or decreased $\mathrm{T}$ cell killing activity. $\mathrm{CD}^{+} \mathrm{T}$ cells infiltrated the lymphomas that formed in LMP1-KO EBV-infected hNSG(thy) mice, even when treated with OKT3 (Figure 11B).

Some EBV-positive human DLBCLs contain large numbers of infiltrating $C D 4^{+} T$ cells. A subset of human DLBCLs (referred to as $\mathrm{T}$ cell/histiocyte-rich large $\mathrm{B}$ cell lymphomas) are infiltrated by high numbers of T cells (41). Since our results in the humanized cord blood model suggested that $\mathrm{CD} 4^{+} \mathrm{T}$ cells may sometimes promote the growth of EBV-positive DLBCLs in humans, we examined the number of $\mathrm{CD} 4^{+} \mathrm{T}$ cells in 4 different EBV-positive, AIDSrelated (non-germinal center type) human DLBCLs. Interestingly, 1 of these DLBCLs, which did not express LMP1, contained a high number of infiltrating $\mathrm{CD} 4^{+} \mathrm{T}$ cells (Supplemental Figure 2). However, since the other 3 tumors (including 2 LMP1- DLBCLs) did not $^{-}$ have many $\mathrm{CD}^{+} \mathrm{T}$ cells (data not shown), additional factors, such as mutation of the cellular $A 20$ gene (also known as TNFAIP3) (12), may also compensate for loss of LMP1 expression in EBVinfected human DLBCLs.

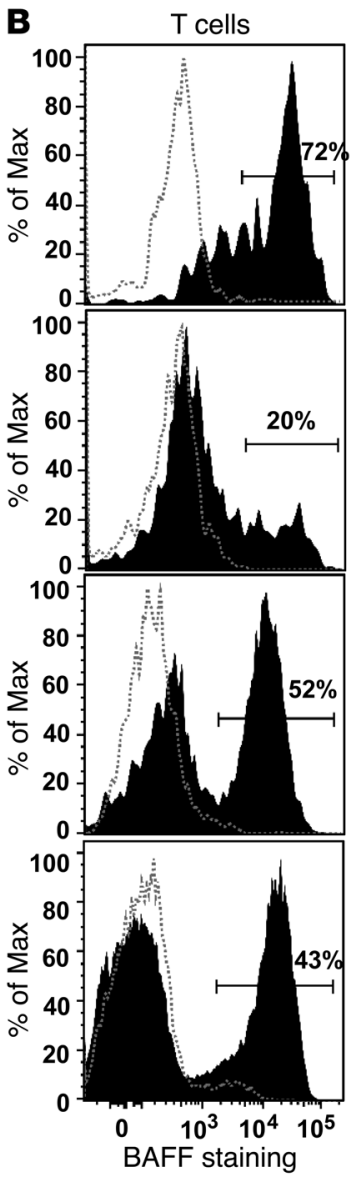

Figure 9. T cells, but not $B$ cells, from LMP1-KO EBV tumors express CD40L, and T cells from tumors express high levels of BAFF. Cells isolated from tumors or spleens of mice injected with LMP1-KO EBV- or WT EBV-infected cord blood were stained with Abs specific for human CD45, CD19, CD20, CD3, CD4OL, BAFF, or the respective isotypematched negative controls, then analyzed by flow cytometry. Samples were gated on single cells expressing human CD45, CD19, and CD20 (B cells) or CD45 and CD3 (T cells). Black shaded histograms show staining for CD4OL (A) or BAFF (B); dashed gray histograms show staining of the same population of cells by the isotype control. Percentages denote the fraction of $\mathrm{CD} 4 \mathrm{LL}^{+}$or $\mathrm{BAFF}^{+}$cells above the isotype control background.

\section{Discussion}

Numerous EBV-positive lymphomas in humans do not detectably express the major EBV oncoprotein, LMP1, yet retain the viral genome. Because the EBV genome is lost from cells when it does not provide a survival advantage (11), the continued presence of EBV in LMP1- human tumors indicates that the virus must provide a selective advantage to tumor cells, even in the absence of LMP1 expression. Furthermore, the fact that LMP1 enhances T cell-mediated killing of EBV-infected cells by numerous different mechanisms suggests that there is strong selective pressure for EBV-positive tumors in humans to shut down LMP1 expression. However, to our knowledge, the ability of LMP1-deleted EBV to cause lymphomas in vivo had not previously been demonstrated. Here, we showed that LMP1-deleted EBV can indeed cause lymphomas in humanized NSG mice in a CD $4^{+} \mathrm{T}$ cell- and CD40-dependent manner.

Our present results suggest that activated $\mathrm{T}$ cells can at least partially replace the requirement for LMP1 expression in EBVinduced lymphomas by providing a source of CD40 signaling. Since we also found that LMP1-KO EBV was compromised in its ability to cause lymphomas in hNSG(thy) mice, which have functional $\mathrm{T}$ cells due to coengrafted human thymic tissue, it appears that the growth and survival advantage of $\mathrm{LMP1}^{+}$(versus LMP1') lymphoma cells may in some cases outweigh the immunostimulatory effect of LMP1 expression. We conclude that T cells may either promote or inhibit the development of LMP1- lymphomas in humans. Indeed, AIDS patients - who often have hyperstimulat- 
A

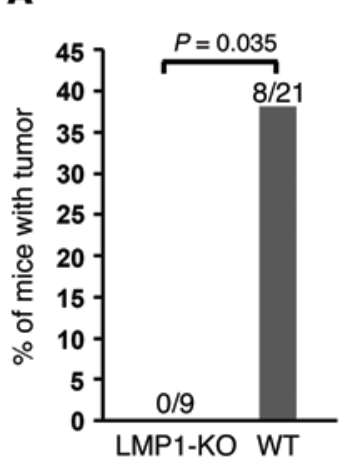

D

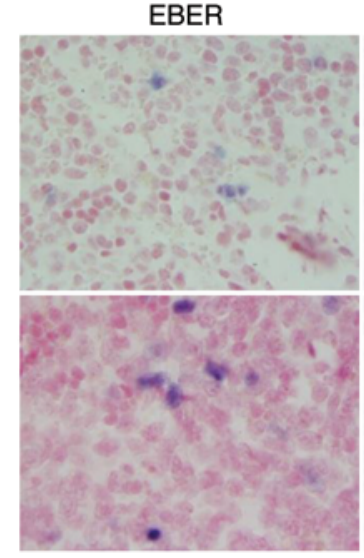

B

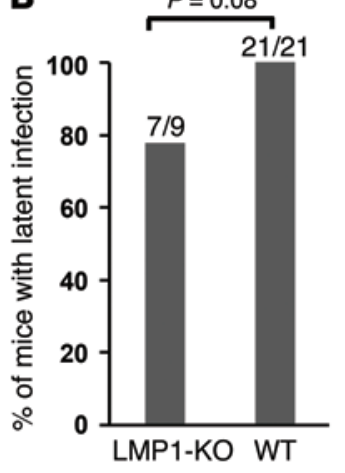

EBNA1

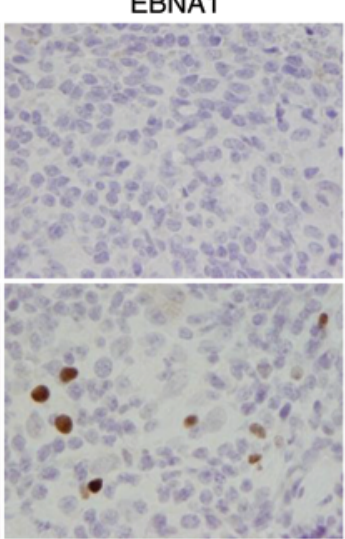

C
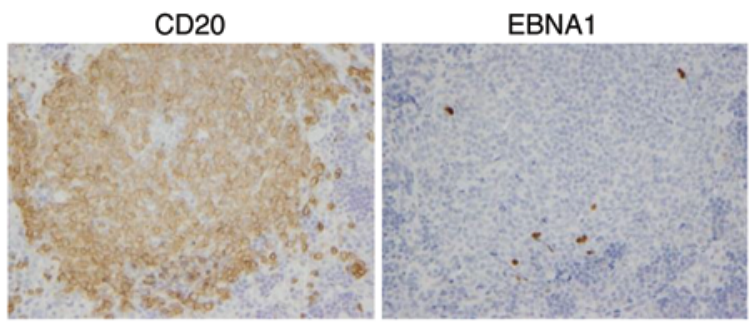

Figure 10. LMP1-KO EBV cannot induce lymphomas in highly immunocompetent hNSG(thy) mice, but can establish long-term viral latency. (A and B) Incidence and percentage of LMP1-KO EBV- and WT EBV-infected hNSG(thy) mice that developed lymphomas (A) or latent EBV infection (B). Data were combined from 4 experiments; 2-tailed Fisher exact test was used for statistical analysis. (C) The spleen of an LMP1-KO EBV-infected hNSG(thy) mice was stained with $\mathrm{CD} 20$ or anti-EBNA1 Ab. A small fraction of $\mathrm{CD} 2 \mathrm{O}^{+} \mathrm{B}$ lymphocytes harbored EBV infection, consistent with viral latency. This animal also had a detectable viral load in the blood at the time of euthanasia. (D) Spleens from 2 LMP1-KO EBV-infected hNSG(thy) mice subjected to EBER ISH and IHC for EBNA1, EBNA2, and BZLF1. Original magnification, $\times 40$ (C); ×100 (D).

ed, yet functionally deficient, T cells (42) - often develop LMP1 DLBCLs (12). CD4OL incorporated into HIV virions (previously shown to activate CD40 signaling in B cells; ref. 43) may provide another source of CD40 signaling to $\mathrm{LMP1}^{-} \mathrm{EBV}$-positive lymphomas in AIDS patients.

The same LMP1-KO EBV used in the current in vivo studies was previously shown to transform B cells with very low efficiency in vitro (approximately 1\% that obtained with WT EBV) in the presence of a continuously provided feeder layer (9), although the LMP1-KO EBV-infected B cells were unable to form lymphomas when injected into SCID mice (9). Our present results suggest that $\mathrm{CD}^{+} \mathrm{T}$ cells allow LMP1-KO EBV-infected B cells to survive in humanized mice, at least in part, by providing a source of CD40 signaling. In addition, $\mathrm{T}$ cells may provide various additional growth factors, cytokines, and signaling ligands essential for the survival and growth of LMP1-KO EBV-infected B cells in NSG mice. One such factor may be BAFF ligand, since peripheral B cells require BAFF for their survival and proliferation (44), and mouse BAFF ligand does not induce signaling through the human BAFF receptor (45). Consistent with this, we found that tumor-associated $\mathrm{T}$ cells expressed very high BAFF levels (Figure 9B). Interestingly, since transgenic expression of the gene encoding LMP1 in mice induces expression of BAFF ligand on B cells (46), WT EBV-infected B cells may be less dependent on T cells (compared with LMP1-KO EBV-infected B cells) as a source for BAFF ligand. Finally, the previous reports showing that $\mathrm{T}$ cells are required for PBLs from seropositive EBV-positive donors to form EBV-positive lymphomas in SCID mice are consistent with prior findings that EBV-infected memory B cells in healthy donors have type I latency and hence do not express LMP1.

Our current finding that CD40-blocking Ab inhibited development of both WT EBV- and LMP1-KO EBV-induced cord blood lymphomas in NSG mice is surprising, given that LMP1 expression is thought to mimic the effect of constitutive CD40 signaling (5-7). Nevertheless, this result is consistent with a previous report showing that WT EBV cannot induce in vitro transformation of $\mathrm{B}$ cells obtained from patients with the hyper-IgM syndrome who have $C D 4 O$ ligand mutations (37). Thus, LMP1 does not completely replace the need for authentic CD40 signaling in EBV-infected B cells. Since CD40 signaling has been previously reported to induce LMP1 expression in an EBV-positive Hodgkin lymphoma cell line with type I latency (47), it is possible that CD40 signaling also increases LMP1 expression in the cord blood model. Previously, EBV infection was shown to induce expression of CD40L on EBV-infected B cells in vitro (37). Here, we showed that CD4OL induction on EBV-infected B cells in vivo in the cord blood humanized mouse model required LMP1 expression. In contrast, T cells expressed CD4OL in animals infected with either EBV, but not 
A

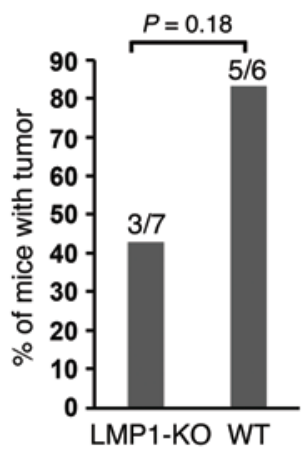

B

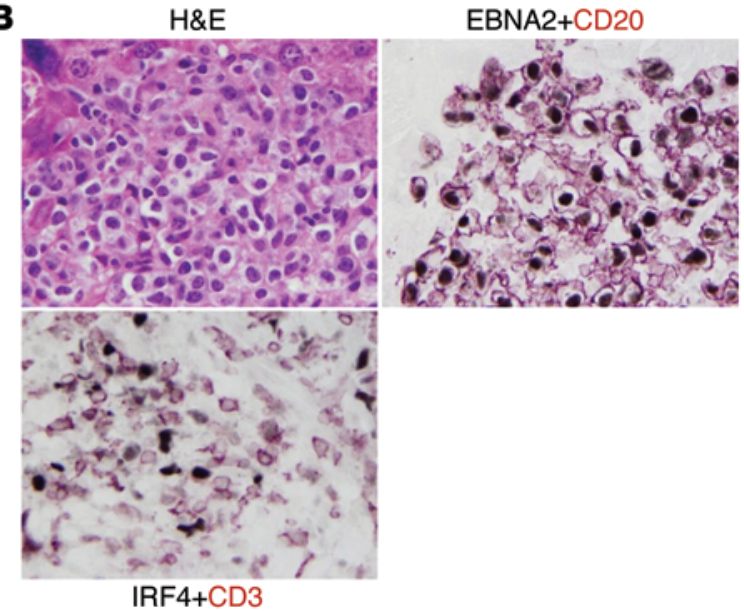

Figure 11. LMP1-KO EBV can induce lymphomas in a subset of hNSG(thy) mice treated with the T cell receptor Ab OKT3. (A) Incidence and percentage of LMP1-KO EBV- and WT EBV-infected hNSG(thy) mice that developed lymphomas when treated with OKT3 Ab. Data were combined from 2 experiments; 2-tailed Fisher exact test was used for statistical analysis. (B) An LMP1-KO EBV-infected lymphoma invading the liver in an OKT3-treated infected hNSG(thy) mouse was stained for $\mathrm{H} \& \mathrm{E}$, costained for EBNA2 (purple) and CD2O (red), or costained for CD3 (red) and IRF4 (purple). Even with OKT3 treatment, IRF4+ EBV-infected lymphoma cells were infiltrated by $\mathrm{CD}^{+} \mathrm{T}$ cells. Neoplastic cells coexpressed EBNA2 and CD2O, which indicated that they are B lymphocytes with type III latency. Original magnification, $\times 100$. in uninfected cord blood-injected animals. This finding helps to explain why LMP1-KO EBV, but not WT EBV, required coinjected $\mathrm{T}$ cells to form $\mathrm{B}$ cell lymphomas in cord blood humanized mice. While it remains possible that the results of anti-CD40 treatment experiment were due to depletion of $B$ cells by this $\mathrm{mAb}$, the same $\mathrm{Ab}$ used in these studies was not found to significantly deplete $\mathrm{B}$ cells in a primate model (38).

The creation of an animal model in which LMP1-deleted EBV causes lymphomas should be highly useful for examining the transforming functions of other latent EBV genes (and viral microRNAs) in this process. The EBV LMP2A protein, which mimics the effects of constitutively active $B$ cell receptor (BCR) (3), may play an essential role in promoting the development of LMP1-KO EBV lymphomas. Like LMP1, LMP2A activates key cell survival signaling pathways, including the PI3K/AKT pathway (48). The highly proliferative nature of the LMP1-KO lymphomas (indicated by their high level of Ki67 expression) may also require expression of the EBV EBNA2 protein, which mimics the effect of constitutively activated Notch signaling (3). The EBV-encoded protein EBNA3C, which inhibits expression of the cell cycle inhibitor p16 (49), may also promote proliferation of the LMP1-KO EBVinfected cells. Notably, EBNA3C was also recently shown to stabilize the IRF4 protein in EBV-infected B cells (32), and we found that the LMP1-KO EBV-induced lymphomas expressed a high level of IRF4. IRF4 is not only an essential growth and survival factor for activated human DLBCLs (34), but is also required for survival of EBV-transformed LCLs in vitro $(32,33)$. $T$ cell-derived CD40 signaling may also help to induce IRF4 expression in LMP1-KO EBVinduced lymphomas (35). Finally, the viral encoded microRNAs (a portion of which are expressed by the B95.8 strain of EBV) were recently shown to promote the survival of BLs by inhibiting apoptosis (11), and likely contribute to the survival of LMP1-KO EBV-induced lymphomas.

The failure of the $\mathrm{T}$ cells to control EBV-driven lymphomas in cord blood-injected NSG mice may partially reflect the immaturity of cord blood-derived T cells, as well as the absence of EBV-directed memory T cells. Nevertheless, $T$ cell lines directed against EBV antigens, which are capable of killing EBV-infected $\mathrm{B}$ cells, can be obtained from cord blood in vitro (50). Thus, EBVinfected lymphoma cells may also have mechanisms for actively inhibiting $\mathrm{T}$ cell-mediated killing. It will be important to determine whether EBV-induced lymphoma cells in this model, and in humans, express high levels of the $\mathrm{T}$ cell-inhibitory ligands programmed death-ligand 1 (PD-L1) and PD-L2. If so, blockade of programmed cell death protein 1 (PD1) signaling (51) may be a particularly efficacious approach for treating EBV-positive tumors, which express virally encoded antigens that should be easily recognized by functional $\mathrm{T}$ cells.

Finally, given our finding that a CD40-blocking Ab inhibited the ability of both WT EBV and LMP1-KO EBV to induce cord blood lymphomas in NSG mice, it is tempting to speculate that blockade of CD40 signaling may be useful for treating certain forms of EBVinduced lymphomas in humans. A CD40-blocking Ab is already being tested in human subjects for potential use as an immunosuppressive agent to prevent organ rejection in transplant patients. Although CD4OL-blocking Abs proved to be toxic in humans because of unexpected thromboembolic effects (due to CD4OL expression on platelets), to date, $\mathrm{CD} 40$ receptor-blocking Abs have not been found to have similar toxicity in humans $(52,53)$. Nevertheless, since CD40-blocking Abs are predicted to be immunosuppressive, they might be most useful for inhibiting the development of EBV-induced lymphomas in organ transplant patients, while simultaneously preventing organ rejection. It will be important in future studies to determine whether CD40 receptor-blocking Abs not only prevent the development of EBV-induced lymphomas, but also cause regression of established lymphomas.

\section{Methods}

EBVs. A WT (B95-8 strain) EBV bacmid p2089 (EB14), which expresses GFP and a hygromycin B resistance gene, was constructed using bacterial artificial chromosome technology as described previously (54) and was a gift from H.-J. Delecluse (Deutsches Krebsforschungszentrum, Heidelberg, Germany). The LMP1-KO EBV, missing amino acids 1-384 (originally called $\triangle \mathrm{LMP1}$ ), was derived by mutagenesis of the p2089 bacmid as previously described (9) and was a gift from W. Hammerschmidt (Helmholtz Zentrum München-Haematologikum, München, Germany).

Humanized NSG mice. Immunodeficient NSG (NOD/LtSz$s c i d / I L 2 R \gamma^{\text {mull}}$ ) mice were purchased from Jackson Labs (catalog no. 005557). hNSG(thy) mice, which are engrafted both with purified 


\section{Table 1. Abs used for IHC}

$\begin{array}{lccc}\text { Ab } & \text { Clone } & \text { Source } & \text { Dilution } \\ \text { CD20 } & \text { H1 } & \text { BD Biosciences - Pharmingen } & 1: 600 \\ \text { CD3 } & \text { Polyclonal } & \text { DakoCytomation } & 1: 200 \\ \text { LMP1 } & \text { CS.1-4 } & \text { DakoCytomation } & 1: 600 \\ \text { EBNA1 } & \text { EB14 } & \text { Cift of R.R. Burgess } & 1: 100 \\ \text { EBNA2 } & \text { PE2 } & \text { Leica Microsystems } & 1: 100 \\ \text { BZLF1 } & \text { BZ1 } & \text { Santa Cruz Biotechnology Inc. } & 1: 200 \\ \text { K light chain } & \text { L1C1 } & \text { Imgenex } & 1: 100 \\ \lambda \text { light chain } & \text { IC0106 } & \text { Imgenex } & 1: 100 \\ \text { Ki67 } & \text { Ki67 } & \text { Santa Cruz Biotechnology Inc. } & 1: 100 \\ \text { IRF4 } & \text { MUM1p } & \text { Santa Cruz Biotechnology Inc. } & 1: 50 \\ \text { c-MYC } & \text { Y69 } & \text { Abcam Inc. } & 1: 50\end{array}$

AUniversity of Wisconsin-Madison, Madison, Wisconsin, USA.

human $\mathrm{CD} 34^{+}$cells isolated from fetal liver and with human fetal thymus (obtained from the same donor), were derived as previously described $(26,30)$. Alternatively, commercially purchased CD34-depleted human cord blood mononuclear cells (AllCells LLC, catalog no. CB117) were mock-infected or infected with WT EBV or LMP1-KO EBV in vitro for 1.5 hours, after which $12 \times 10^{6}-25 \times 10^{6}$ cells were injected i.p. into 3- to 5-week-old NSG mice. Both WT EBV- and LMP1-KO EBV-infected animals were included in all cord blood experiments so that results could be compared using the same sets of cord blood. In some experiments, the cord blood was depleted of T cells using pan-T cell isolation kit (Miltenyi Biotec Inc., catalog no. 130-096-535), or B cells were positively selected using B cell isolation kit (Miltenyi Biotec Inc., catalog no. 130-093-660), prior to EBV infection (or mock infection). Since both manipulations gave similar results in terms of tumor development, they were combined when calculating the effect of T cell depletion on the ability of WT EBV versus LMP1-KO EBV to induce cord blood lymphomas in NSG mice.

Production of infectious virus. Infectious viral particles were produced from 293 cell lines stably infected with WT EBV or LMP1-KO EBV after transfection with EBV BZLF1 and GP110 expression vectors as previously described (26). EBV was titered on Raji cells using the Green Raji cell assay as previously described (26).

$E B V$ infection of mice. hNSG(thy) mice were injected i.p. with 30,000 infectious particles of WT EBV or LMP1-KO EBV (diluted in PBS; final volume, $200 \mu \mathrm{l}$ ) approximately 10 weeks after engraftment of human cells. In the cord blood experiments, cord blood was mock-infected or infected with 30,000 IU WT EBV or LMP1-KO EBV for 1.5 hours in vitro, then injected i.p. into NSG mice (diluted in PBS; final volume, $200 \mu \mathrm{l})$. Mice were sacrificed at day 60 after infection in hNSG(thy) mice, unless they developed symptoms requiring euthanasia earlier. In the EBV-infected cord blood animal experiments, as soon as 1 or more of the EBV-infected animals needed to be euthanized (generally around 30-40 days after infection), the rest of the infected (or mock-infected) animals of that particular donor experiment were also sacrificed, such that the frequency of WT EBV- and LMP1-KO EBV-infected tumors could be compared at similar time points after infection and in cells derived from the same donor.

Analysis of EBV infection and tumors. After euthanasia, multiple different organs (including the lungs, transplanted thymus, spleen, pancreas, liver, gall bladder, mesenteric fat, and abdominal lymph nodes) were formalin fixed, then examined using various techniques to deter- mine whether animals had persistent EBV infection and/or EBV-positive lymphomas and to assess the viral protein expression pattern. Analysis performed for all animals included H\&E staining and IHC staining using Abs directed against CD2O (B cell marker), CD3 (T cell marker), and EBV proteins EBNA1, EBNA2, LMP1, and BZLF1. In some animals, EBER ISH studies were performed using the PNA ISH Detection Kit (DakoCytomation) according to the manufacturer's protocol, as previously described (26). In some animals, DNA was isolated from paraffin-fixed slides using the QIAamp DNA FFPE Tissue Kit (Qiagen, catalog no. 56404) and then PCR amplified using primers specific for the EBV LMP1 gene (left, AGTCATCGTGGTGGTGTTCA; right, TTACCACACCCCCACTTTTC; 291 bp) or BZLF1 gene promoter (left, ACCAGCCTCCTCTGTGATGT; right, TTTGGACGAACTGACCACAA; 298 bp) to confirm that LMP1KO EBV-induced tumors were not contaminated by WT EBV. PCR was performed in $50 \mu \mathrm{l}$ reaction volume containing $0.2 \mu \mathrm{mol} / \mathrm{l}$ primers and $1 \mathrm{U}$ Taq DNA polymerase, under the following conditions: $95^{\circ} \mathrm{C}$ for 2 minutes; 30 cycles of $95^{\circ} \mathrm{C}$ for 30 seconds, $58^{\circ} \mathrm{C}$ for 30 seconds, and $72^{\circ} \mathrm{C}$ for 40 seconds; $72^{\circ} \mathrm{C}$ for 5 minutes. PCR products were visualized with ethidium bromide on $1 \%$ agarose gel. In some animals, RNA was isolated from paraffin-fixed tumor slides using the FFPE RNA Purification Kit (NORGEN Biotek Corp., catalog no. 25300), then reversed transcribed using the Reverse Transcription System Kit (Promega, catalog no. A3500). cDNA was then amplified using primers that specifically detect the EBV Cp-derived EBNA1 transcript (TGGCGTGTGACGTGGTGTAA and CATGATTCACACTTAAAGGA) or the Qp-derived transcript (GTGCGCTACCGGATGGCG and CATGATTCACACTTAAAGGA). GAPDH primers were GGAAGGTGAAGGTCGGAGTCA and ATGGGTGGAATCATTGGAACA.

Anti-CD40, anti-CD3, and anti-CD4 Ab treatment. The anti-CD3 $\mathrm{Ab}$ OKT3 was purchased from Imgenex. Mice received $2 \mu \mathrm{g} / \mathrm{d}$ OKT3 starting 1 day after EBV infection and continuing for 6 days per week (alternating i.p. and i.v. route) until the time of euthanasia. The blocking anti-CD40 Ab 2C10R4 was obtained through the NIH Nonhuman Primate Reagent Resource. This rhesus recombinant (chimeric) form of the previously described $\mathrm{Ab} 2 \mathrm{C} 10$ blocks both human and rhesus CD40 signaling without inducing CD40 stimulation or causing B cell killing (38). Mice were given $\mathrm{Ab}$ injections (100 $\mu \mathrm{g}$ i.p.) 3 times weekly, starting 1 day after cord blood injection. The anti-CD4 depleting Ab CD4R1 was obtained from the NIH Nonhuman Primate Reagent Resource. Mice were given Ab injections (100 $\mu$ g i.p.) 3 times weekly, starting day 4 after cord blood injection.

IHC. Formalin-fixed, paraffin-embedded tissue sections were deparaffinized and then examined by IHC as previously described $(26,27)$. Abs used are listed in Table 1. IHC staining of CD4 (clone 4B12, dilution 1:80; Leica Microsystems) was accomplished using the Bond III Autostainer (Leica Microsystems). Formalin-fixed, paraffinembedded tissue microarray (TMA) sections were first baked and deparaffinized. Antigen retrieval was followed by heating the slides in Bond Epitope Retrieval Solution 2 (ER2) (Leica Microsystems) at $99^{\circ} \mathrm{C}-100^{\circ} \mathrm{C}$ for 30 minutes. Sections were then subjected to sequential incubation with the endogenous peroxidase block for 5 minutes, primary $\mathrm{Ab}$ for 25 minutes, post-primary (equivalent to secondary $\mathrm{Ab}$ ) for 15 minutes, polymer (equivalent to tertiary $\mathrm{Ab}$ ) for 25 minutes, diaminobenzidine (DAB) for 10 minutes, and hematoxylin (Bond Polymer Define Detection; Leica Microsystems) for 5 minutes. Finally, sections were dehydrated in $100 \%$ ethanol and mounted in Cytoseal XYL (Richard-Allan Scientific). 
Q-PCR to measure EBV viral load in plasma. EBV viral load in plasma samples was measured using TaqMan Q-PCR technology with primers targeting the EBV genome (55). DNA was extracted using High Pure Viral Nucleic Acid Kit (Roche) on $200 \mu \mathrm{l}$ plasma each, except when less volume was available and the calculated result was extrapolated accordingly. DNA was eluted in $50 \mu \mathrm{l}$ nuclease-free water, and Q-PCR targeting the EBV BamH1W segment was done in almost duplicate ( $5 \mu \mathrm{l}$ versus $10 \mu \mathrm{l}$ input DNA). TaqMan Exogenous Internal Positive Control (IPC) was spiked before DNA extraction and quantified in the same well, thus serving as a marker of the efficacy of extraction and amplification.

FACS analysis. Spleen or tumor tissues were mechanically dissected using a syringe hub, then filtered through a $70-\mu \mathrm{M}$ cell strainer (Fisher Scientific). Cells were spun down, washed in PBS, and then diluted into PBS at a concentration of $2 \times 10^{6}-4 \times 10^{6}$ cells $/ \mathrm{ml}$. Cells were stained with the following Abs (all from Biolegend): APC-conjugated CD45 (catalog no. 304011), BV510-conjugated CD3 (catalog no. 317332), FITC-conjugated CD19 (catalog no. 302206), FITC-conjugated CD20 (catalog no. 302304), PE-conjugated CD4OL (catalog no. 310806), and PE-conjugated CD257 (BAFF) (catalog no. 318606). Appropriate isotype controls were used in each case. Ab staining was analyzed using a LSR II BD flow cytometer.

Statistics. Mstat Software (http://mcardle.wisc.edu/mstat/download/index.html) was used to statistically analyze the data. For tumor formation comparison, the $P$ value was calculated using a 2-tailed Fisher exact test. For viral load comparison, the $P$ value was calculated using the Wilcoxon rank-sum test. A $P$ value less than 0.05 was considered significant.

Study approval. All animal experiments were approved by the University of Wisconsin-Madison IACUC and conducted in accordance with the NIH Guide for the Care and Use of Laboratory Animals. For human AIDS-related lymphomas, cases were collected from the Department of Pathology and Laboratory Medicine of Weill Cornell Medical College. All human samples, obtained with IRB and biospecimen use approval, were residual cases after diagnosis.

\section{Acknowledgments}

We thank Liz Barlow for help with animal experiments, Amy Chadburn and Yifang Liu for help with human tumor slide staining, and Eric Johannsen and Bill Sugden for reviewing the manuscript. This research was supported by NIH grants P01CA22443 and R01CA174462 and by University of Wisconsin Cancer Center Support Grant P30CA014520.

Address correspondence to: Shannon C. Kenney, University of Wisconsin, 7531 Wi Institute Medical Research, 1111 Highland Ave., Madison, Wisconsin 53705, USA. Phone: 608.265.0533; E-mail: skenney@wisc.edu.
1. Vereide D, Sugden B. Insights into the evolution of lymphomas induced by Epstein-Barr virus. Adv Cancer Res. 2010;108:1-19.

2. Vereide DT, Sugden B. Lymphomas differ in their dependence on Epstein-Barr virus. Blood. 2011;117(6):1977-1985.

3. Kieff ED, Rickinson AB. Epstein-Barr Virus and its replication. In: Fields BN, Knipe DM, Howley PM, Griffin DE eds. Fields' Virology. 5th ed. Philadelphia, Pennsylvania, USA: Wolters Kluwer Health/Lippincott Williams \& Wilkins; 2007:2603-2654.

4. Rickinson AB, Kieff ED. Epstein-Barr Virus. In: Fields BN, Knipe DM, Howley PM, Griffin DE eds. Fields' Virology. 5th ed. Philadelphia, Pennsylvania, USA: Wolters Kluwer Health/Lippincott Williams \& Wilkins; 2007:2655-2700.

5. Rastelli J, et al. LMP1 signaling can replace CD40 signaling in B cells in vivo and has unique features of inducing class-switch recombination to IgG1. Blood. 2008;111(3):1448-1455.

6. Graham JP, Arcipowski KM, Bishop GA. Differential B-lymphocyte regulation by CD40 and its viral mimic, latent membrane protein 1 . Immunol Rev. 2010;237(1):226-248.

7. Kilger E, Kieser A, Baumann M, Hammerschmidt W. Epstein-Barr virus-mediated B-cell proliferation is dependent upon latent membrane protein 1 , which simulates an activated CD40 receptor. EMBO J. 1998;17(6):1700-1709.

8. Shair KH, Bendt KM, Edwards RH, Bedford EC, Nielsen JN, Raab-Traub N. EBV latent membrane protein 1 activates Akt, $\mathrm{NF} \kappa \mathrm{B}$, and Stat 3 in B cell lymphomas. PLoS Pathog. 2007;3(11):e166.

9. Dirmeier U, Neuhierl B, Kilger E, Reisbach G, Sandberg ML, Hammerschmidt W. Latent membrane protein 1 is critical for efficient growth transformation of human B cells by Epstein-Barr virus. Cancer Res. 2003;63(11):2982-2989.

10. Kelly GL, et al. Different patterns of EpsteinBarr virus latency in endemic Burkitt lymphoma (BL) lead to distinct variants within the BLassociated gene expression signature. J Virol. 2013;87(5):2882-2894.

11. Vereide DT, et al. Epstein-Barr virus maintains lymphomas via its miRNAs. Oncogene. 2014;33(10):1258-1264.

12. Giulino L, et al. A20 (TNFAIP3) genetic alterations in EBV-associated AIDS-related lymphoma. Blood. 2011;117(18):4852-4854.

13. Zhang B, et al. Immune surveillance and therapy of lymphomas driven by Epstein-Barr virus protein LMP1 in a mouse model. Cell. 2012;148(4):739-751.

14. Brooks JM, Lee SP, Leese AM, Thomas WA, Rowe $\mathrm{M}$, Rickinson AB. Cyclical expression of EBV latent membrane protein 1 in EBV-transformed $\mathrm{B}$ cells underpins heterogeneity of epitope presentation and CD8+ T cell recognition. J Immunol. 2009;182(4):1919-1928.

15. Lee DY, Sugden B. The LMP1 oncogene of EBV activates PERK and the unfolded protein response to drive its own synthesis. Blood. 2008;111(4):2280-2289.

16. Pratt ZL, Zhang J, Sugden B. The latent membrane protein 1 (LMP1) oncogene of Epstein-Barr virus can simultaneously induce and inhibit apoptosis in B cells. J Virol. 2012;86(8):4380-4393.

17. Le Clorennec C, et al. Molecular basis of cytotoxicity of Epstein-Barr virus (EBV) latent membrane protein 1 (LMP1) in EBV latency III B cells: LMP1 induces type II ligand-independent autoactivation of CD95/Fas with caspase 8-mediated apoptosis. J Virol. 2008;82(13):6721-6733.
18. MacArthur GJ, Wilson AD, Birchall MA, Morgan AJ. Primary CD4+ T-cell responses provide both helper and cytotoxic functions during Epstein-Barr virus infection and transformation of fetal cord blood B cells. J Virol. 2007;81(9):4766-4775.

19. Rowe M, Young LS, Crocker J, Stokes H, Henderson S, Rickinson AB. Epstein-Barr virus (EBV) associated lymphoproliferative disease in the SCID mouse model: implications for the pathogenesis of EBV-positive lymphomas in man. J Exp Med.1991;173(1):147-158.

20. Clinchy B, Vitetta ES. The use of an anti-CD3 immunotoxin to prevent the development of lymphoproliferative disease in SCID/PBL mice. JImmunol Methods. 1998;218(1-2):141-153.

21. Johannessen I, Asghar M, Crawford DH. Essential role for T cells in human B-cell lymphoproliferative disease development in severe combined immunodeficient mice. Br J Haematol. 2000;109(3):600-610.

22. Coles RE, Boyle TJ, DiMaio JM, Berend KR, Via DF, Lyerly HK. T cells or active Epstein-Barr virus infection in the development of lymphoproliferative disease in human B cell-injected severe combined immunodeficient mice. Ann Surg Oncol. 1994;1(5):405-410.

23. Veronese ML, et al. Lymphoproliferative disease in human peripheral blood mononuclear cellinjected SCID mice. I. T lymphocyte requirement for B cell tumor generation. J Exp Med. 1992;176(6):1763-1767.

24. Chijioke O, et al. Human natural killer cells prevent infectious mononucleosis features by targeting lytic Epstein-Barr virus infection. Cell Rep. 2013;5(6):1489-1498.

25. Cocco M, et al. CD34+ cord blood cell-transplanted 
Rag2 $^{-/} \gamma(\mathrm{c})^{-/-}$mice as a model for Epstein-Barr virus infection. Am JPathol. 2008;173(5):1369-1378.

26. Ma SD, et al. A new model of Epstein-Barr virus infection reveals an important role for early lytic viral protein expression in the development of lymphomas. J Virol. 2011;85(1):165-177.

27. Ma SD, et al. An Epstein-Barr Virus (EBV) mutant with enhanced BZLF1 expression causes lymphomas with abortive lytic EBV infection in a humanized mouse model. JVirol. 2012;86(15):7976-7987.

28. Strowig T, et al. Priming of protective T cell responses against virus-induced tumors in mice with human immune system components. JExp Med.2009;206(6):1423-1434.

29. Shultz LD, Brehm MA, Garcia-Martinez JV, Greiner DL. Humanized mice for immune system investigation: progress, promise and challenges. Nat Rev Immunol. 2012;12(11):786-798.

30. Rajesh D, et al. Th1 and Th17 immunocompetence in humanized NOD/SCID/IL2rynull mice. Hum Immunol. 2010;71(6):551-559.

31. Prince S, Keating S, Fielding C, Brennan P, Floettmann E, Rowe M. Latent membrane protein 1 inhibits Epstein-Barr virus lytic cycle induction and progress via different mechanisms. JVirol. 2003;77(8):5000-5007.

32. Banerjee S, et al. The EBV Latent Antigen $3 \mathrm{C}$ Inhibits Apoptosis through Targeted Regulation of Interferon Regulatory Factors 4 and 8. PLoS Pathog. 2013;9(5):e1003314.

33. Wang $L$, et al. Oncogenic IRFs provide a survival advantage for Epstein-Barr virus- or human T-cell leukemia virus type 1-transformed cells through induction of BIC expression. JVirol. 2011;85(16):8328-8337.

34. Yang Y, et al. Exploiting synthetic lethality for the therapy of $\mathrm{ABC}$ diffuse large $\mathrm{B}$ cell lymphoma. Cancer Cell. 2012;21(6):723-737.

35. Aldinucci D, et al. IRF 4 is modulated by CD4OL and by apoptotic and anti-proliferative signals in Hodgkin lymphoma. Br J Haematol. 2010;148(1):115-118.
36. Shaffer AL, et al. IRF 4 addiction in multiple myeloma. Nature. 2008;454(7201):226-231.

37. Imadome K, Shirakata M, Shimizu N, Nonoyama $\mathrm{S}$, Yamanashi Y. CD40 ligand is a critical effector of Epstein-Barr virus in host cell survival and transformation. Proc Natl Acad Sci U S A. 2003;100(13):7836-7840.

38. Lowe $\mathrm{M}$, et al. A novel monoclonal antibody to $\mathrm{CD} 40$ prolongs islet allograft survival. $\mathrm{Am} J$ Transplant. 2012;12(8):2079-2087.

39. Ferran C, Bach JF, Chatenoud L. In vivo T cell activation properties of anti-T cell monoclonal antibodies. Exp Nephrol. 1993;1(2):83-89.

40. Ellenhorn JD, Woodle ES, Ghobreal I, Thistlethwaite JR, Bluestone JA. Activation of human $\mathrm{T}$ cells in vivo following treatment of transplant recipients with OKT3. Transplantation. 1990;50(4):608-612.

41. Pittaluga S, Jaffe ES. T-cell/histiocyte-rich large B-cell lymphoma. Haematologica. 2010;95(3):352-356.

42. Haas A, Zimmermann K, Oxenius A. Antigendependent and -independent mechanisms of $T$ and B cell hyperactivation during chronic HIV-1 infection. J Virol. 2011;85(23):12102-12113.

43. Epeldegui M, Thapa DR, De la Cruz J, Kitchen S, Zack JA, Martinez-Maza O. CD40 ligand (CD154) incorporated into HIV virions induces activation-induced cytidine deaminase (AID) expression in human B lymphocytes. PLoS One. 2010;5(7):e11448.

44. Boneparth A, Davidson A. B-cell activating factor targeted therapy and lupus. Arthritis Res Ther. 2012;14(suppl 4):S2.

45. Schmidt MR, Appel MC, Giassi LJ, Greiner DL, Shultz LD, Woodland RT. Human BLyS facilitates engraftment of human PBL derived $\mathrm{B}$ cells in immunodeficient mice. PLoS One. 2008;3(9):e3192.

46. He B, Raab-Traub N, Casali P, Cerutti A. EBVencoded latent membrane protein 1 cooperates with BAFF/BLyS and APRIL to induce T cellindependent Ig heavy chain class switching.
JImmunol. 2003;171(10):5215-5224.

47. Kis LL, et al. In vitro EBV-infected subline of KMH2, derived from Hodgkin lymphoma, expresses only EBNA-1, while CD40 ligand and IL-4 induce LMP-1 but not EBNA-2. Int $J$ Cancer. 2005;113(6):937-945.

48. Portis T, Longnecker R. Epstein-Barr virus (EBV) LMP2A mediates B-lymphocyte survival through constitutive activation of the Ras/PI3K/Akt pathway. Oncogene. 2004;23(53):8619-8628.

49. Skalska L, White RE, Parker GA, Sinclair AJ, Paschos K, Allday MJ. Induction of p16(INK4a) is the major barrier to proliferation when Epstein-Barr virus (EBV) transforms primary B cells into lymphoblastoid cell lines. PLoS Pathog. 2013;9(2):e1003187.

50. Wilson AD, Morgan AJ. Primary immune responses by cord blood CD4(+) T cells and NK cells inhibit Epstein-Barr virus B-cell transformation in vitro. JVirol. 2002;76(10):5071-5081.

51. Yao S, Zhu Y, Chen L. Advances in targeting cell surface signalling molecules for immune modulation. Nat Rev Drug Discov. 2013;12(2):130-146.

52. Kasran A, et al. Safety and tolerability of antagonist anti-human CD40 Mab ch5D12 in patients with moderate to severe Crohn's disease. Aliment Pharmacol Ther. 2005;22(2):111-122.

53. Fanale M, et al. Phase IA/II, multicentre, openlabel study of the CD40 antagonistic monoclonal antibody lucatumumab in adult patients with advanced non-Hodgkin or Hodgkin lymphoma. Br J Haematol. 2014;164(2):258-265.

54. Delecluse HJ, Hilsendegen T, Pich D, Zeidler R, Hammerschmidt W. Propagation and recovery of intact, infectious Epstein-Barr virus from prokaryotic to human cells. Proc Natl Acad Sci U S A. 1998;95(14):8245-8250.

55. Ryan JL, Fan H, Glaser SL, Schichman SA, RaabTraub N, Gulley ML. Epstein-Barr virus quantitation by real-time PCR targeting multiple gene segments: a novel approach to screen for the virus in paraffin-embedded tissue and plasma. JMol Diagn. 2004;6(4):378-385. 